damage (in 36 joints or joint groups) and the JADI-E extraarticular damage (in 5 different organs/systems: ocular, musculoskeletal excluding joints, cutaneous, endocrine, any organ/system).

Results: A total of 953 patients $(67.2 \%$ female, mean age 7.9 years (SD 4.8)) with JIA were included in ICON after a median disease duration of 6 months (IQR: $3.0-11.1)$. About half of the patients (46\%) had oligoarthritis, followed by rheumatoid factor-negative polyarthritis (RF-PA) $(26 \%)$ and enthesitis-related arthritis (11\%). The mean disease activity score cJADAS10 was $9.8(6.2)$ and the mean $\mathrm{CHAQ}$ was $0.57(0.69)$ at enrolment. Any damage was reported for 58 patients (8.6\%) at the 3-year-Follow-up (FU) (mean JADI-A 0.17, mean JADI-E 0.06, JADI-A >0: 6.1\%, JADI-E >0: 3.1\%). At the 4 year (mean JADI-A 0.17, mean JADI-E 0.07) and 6-year-FU (mean JADI-A 0.13, mean JADI-E 0.12), 8.6\% and $10.7 \%$ of patients had any damage. The number of patients with articular damage did not change during FU (6-year-FU: 6.5\%), whereas the proportion of patients with extra-articular damage slightly increased (6-year-FU: 5.0\%). At the 6-year$\mathrm{FU}$, the most frequently scored joints were the knee joints, followed by the wrist. JADI-E was dominated by eye damage. Among the JIA categories, patients with RF+PA showed most frequently damage (16.7\%), followed by patients with enthesitis-related arthritis (15.4\%) and extended oligoarthritis (14.3\%) at the 6 year FU. The JADI-A score significantly correlated $(r=0.27, p<0.001)$ with the number of active joints and JADI-E with the CJADAS10 ( $r=0.14, p=0.041)$ However, there was no significant association between the JADI scores and quality of life (PedsQL), and functional limitations $(C H A Q$, all $r<0.05)$.

Conclusions: About one in ten patients with JIA has developed any damage three, four and six years after disease onset. Thus, a relevant increase in damage over time does not occur under current therapeutic conditions. Articular and extraarticular damage is similarly frequent.

Acknowledgements: ICON is funded by the Federal Ministry of Research (FKZ: 01ER0812)

Disclosure of Interest: None declared

DOI: 10.1136/annrheumdis-2018-eular.6273

\section{THU0553 TNF-INHIBITOR AND LEFLUNOMIDE COMBINATION THERAPY IN POLYARTICULAR JUVENILE IDIOPATHIC ARTHRITIS IN CLINICAL PRACTICE - LESSONS FROM THE GERMAN BIOLOGICS JIA REGISTRY (BIKER)}

M. Napp ${ }^{1}, \mathrm{G}$. Horneff ${ }^{1,2}$, on behalf of BIKER registry working group. ${ }^{1}$ ASKLEPIOS, Sankt Augustin; ${ }^{2}$ University of Cologne, Cologne, Germany

Background: Leflunomide has been shown to be a safe and effective therapy for adult rheumatoid arthritis.

Objectives: Safety and efficacy of combination of TNF inhibitors with leflunomide versus methotrexate for treatment of polyarticular-course juvenile idiopathic arthritis (pcJIA) were assessed in the prospective BIKER registry 2000-2016.

Methods: 3 cohorts of pcJIA patients ageing 3-17 years were analysed: Patients receiving leflunomide starting a TNF inhibitor, ${ }^{1}$ a TNF inhibitor starting leflunomide ${ }^{2}$ methotrexate starting a TNF inhibitor. ${ }^{3}$ Efficacy was determined using the JADAS response criteria, JADAS-10 minimal disease activiy (MDA) and remission. Safety assessments were based on adverse events reports from the responsible physician.

Results: We identified 94 patients treated with Leflunomid-TNF-inhibitor in combination. 44 started a TNF-inhibitor on background Leflunomide, 50 started Leflunomide on background TNF inhibitor. 1361 patients starting a TNF-inhibitor on background Methotrexate served as control group. Differences in patients' chararteristics at baseline limit direct comparison. Patients of cohort 3 had higher CRP, patients of cohort 2, already treated with a biologic, had lower disease activity parameters such as mean active joint count, physician and patient global disease activity judgement and JADAS10. At month 6, upon MTX + TNFi 54.6\%/41.7\%/ $19.6 \%$ and upon LEF + TNFi 35.0\%/36.2\%/13.8\% reached JADAS improvement/ JADAs minimal disease activity/JADAS remission. Thus significantly more patients with MTX +TNFi reached JADAS improvement (OR 2.22 [1.44-3.44]; $p<0.001)$ while there comparable rates of patients reached JADAS-MDA and JADAS-remission. In the LEF cohorts, there were 95 adverse events in 54 patients (58\%) compared to 1845 events in 626 (46\%) on MTX (OR 1.6 [1.0-12.4] $\mathrm{p}=0.031)$. No differences were noted for the number of infections, nausea or elevated transaminases.

Abstract THU0553 - Table 1. Baseline patients' and disease characteristics

\begin{tabular}{lccc}
\hline & $\begin{array}{c}\text { Cohort 1 } \\
(\mathrm{n}=44) \\
\mathrm{LEF}+\mathrm{TNFi}\end{array}$ & $\begin{array}{c}\text { Cohort 2 } \\
(\mathrm{n}=50) \\
\mathrm{TNFi}+\mathrm{LEF}\end{array}$ & $\begin{array}{c}\text { Cohort 3 } \\
(\mathrm{n}=1361) \\
\mathrm{MTX}+\mathrm{TNFi}\end{array}$ \\
\hline Female & $28(64 \%)$ & $40(80 \%)$ & $937(68.8 \%)$ \\
Age at disease onset, median & $6.9(2.1 ; 11.3)$ & $6.2(1.8 ; 9.6)$ & $7.4(2.9 ; 11.5)$ \\
(IQR) & & & \\
Disease duration, median (IQR) & $6.3(3.0 ; 8.5)$ & $5.1(2.0 ; 7.2)$ & $4.1(1.3 ; 6.0)$ \\
ANA positive, $\mathrm{n}(\%)$ & $19(43 \%)$ & $28(56 \%)$ & $647(47.5 \%)$ \\
CRP, median (IQR) & $14.8(3 ; 22)$ & $9.5(0.6 ; 4,5)$ & $20.8(1.4 ; 23)$
\end{tabular}

Active joint count, median (IQR) Physician global, median (IQR) Patient global, median (IQR)

CHAQ-DI, median (IQR) JADAS10, median (IQR)

Abstract THU0553 - Table 2. Improvement at month 6 and tolerability

\begin{tabular}{|c|c|c|c|c|}
\hline & $\begin{array}{c}\text { Cohort } 1 \\
+2 \\
\text { LEF+TNFi }\end{array}$ & $\begin{array}{c}\text { Cohort } 3 \mathrm{MTX} \\
+\mathrm{TNFi}\end{array}$ & $\begin{array}{c}\text { OR (Cohort } 3 \text { vs. } \\
1+2)\end{array}$ & $\mathrm{P}$ \\
\hline JADAS improvement & $35.1 \%$ & $54.6 \%$ & $2.2[1.4-3.4]$ & $<0.001$ \\
\hline $\begin{array}{l}\text { JADAS MDA }(\leq 3.8) / \\
\text { remission }(\leq 1)\end{array}$ & $\begin{array}{l}36.2 \% / \\
13.8 \%\end{array}$ & $41.7 \% / 19.6 \%$ & & n.s. \\
\hline $\mathrm{AE}$ (rate) & $\begin{array}{c}160 \\
(57.4 \%)\end{array}$ & $1845(46 \%)$ & $0.63[0.41-0.96)$ & 0.031 \\
\hline Infections (rate) & $37(23.4 \%)$ & $410(22.2 \%)$ & & n.s. \\
\hline Nausea (rate) & $9(5.3 \%)$ & $156(8.5 \%)$ & & n.s. \\
\hline $\begin{array}{l}\text { Elevated transaminases } \\
\text { (rate) }\end{array}$ & $8(5.3 \%)$ & $112(6.1 \%)$ & & n.s. \\
\hline
\end{tabular}

Conclusions: Combination with both leflunomide and methotrexate to treatment with TNF-inhibitors resulted in clinically meaningful improvements with a comparable rate of patients reaching JADAS-MDA and JADAS-remission at month 6 of treatment. Leflunomide turned out to be a well-tolerated alternative to methotrexate for polyarticular JIA.

Disclosure of Interest: None declared

DOI: 10.1136/annrheumdis-2018-eular.1716

\title{
THU0554 RITUXIMAB (RTX) IN PAEDIATRIC DISEASES: DESCRIBING ITS PHARMACODYNAMICS WITH A FOCUS ON B-CELL DEPLETION AND REPOPULATION, INFECTIONS AND ANTI-DRUG ANTIBODIES
}

A. Nassar-Sheikh Rashid ${ }^{1}$, R. Kampinga ${ }^{1}$, M. Peters ${ }^{1}$, M. Oosterveld ${ }^{2}, T$. W. Kuijpers ${ }^{1}$, J.M. van den Berg ${ }^{1}$, D. Schonenberg-Meinema ${ }^{1}$. ${ }^{1}$ Department of Pediatric Hematology, Immunology, Rheumatology and Infectious Diseases; ${ }^{2}$ Department of Pediatric Nephrology, Emma Children's Hospital, Academic Medical Center, Amsterdam, Netherlands

Background: Rituximab (RTX) is increasingly used in rheumatologic, ${ }^{1,2}$ hematologic $^{3}$ and renal diseases. ${ }^{4}$ The induced $B$ cell depletion can lead to hypogammaglobulinemia and thus an increased risk of infection. ${ }^{5} \mathrm{~B}$ cell depletion is not always achieved, and this has a negative effect on therapeutic response. ${ }^{6}$ Anaphylaxis is a frequent side effect of RTX and has been associated with the occurrence of anti-drug antibodies (ADA) against $\mathrm{RTX}^{7}$

Objectives: To describe in different paediatric patient groups the pharmacodynamics of RTX in children by outcome variables, i.e. success of B-cell depletion and time of $B$ cell repopulation, as well as the risk factors for severe infections and anaphylaxis.

Methods: Patient data of children who received RTX between 2008 and 2017 at our centre were retrospectively collected. Three patient subgroups were defined autoimmune diseases (AID), immune dysregulation (ID) and renal diseases (RD). $B$ cell repopulation was defined as a number above the cut-off value of $B$ cell depletion $\left(=0.050^{*} 10^{\wedge} 6 /\right.$ / or $<2 \%$ of the total amount of lymphocytes).

Results: B cell measurements were performed in 53/55 patients. B cell depletion was not achieved in 9 patients. In the 35 patients with B cell repopulation, median time until repopulation was 155 days (IQR 105-222): in the AID group $(n=12) 129$ days (IQR 77.5-243, $p=0.363$ ), in the ID group $(n=5) 172$ days (IQR 154-181, $\mathrm{p}=0.574)$ and in the RD group $(\mathrm{n}=18) 163$ days (IQR 121-229, $\mathrm{p}=0.847)$. After RTX treatment, in 36 patients IgG levels were measured of which 14 (39\%) had low lgG levels on at least one occasion (median $7 \mathrm{~g} / \mathrm{L}$ [range $0.6-38.1 \mathrm{~g} / \mathrm{L}$ ]) Severe infections leading to hospitalisation occurred in 15 (27\%) cases. An allergic reaction during or directly after RTX infusion was observed in 27 patients (49\%). Anaphylaxis, defined as a systemic allergic reaction, characterised by impairment of airway, breathing, circulation or consciousness, occurred in 10 of these patients (18\% of total cohort). Seven patients were tested for anti-RTX antibodies of whom 6 tested positive: 5 patients in the AID-group and one patient with renal disease. Allergic reactions occurred in all 6 while RTX failed to induce B cell depletion in 4 of these.

Conclusions: Time-to-B-cell-repopulation after RTX did not significantly differ between different paediatric patients groups. Severe infections were common $(27 \%)$ in the cohorts studied. It is unclear from our data whether this is merely related to RTX treatment. Presence of ADA against RTX seems to predict failure of B-cell depletion and/or anaphylaxis after RTX treatment.

REFERENCES:

[1] de Lemos LL, et al. Rev Bras Reumatol 2014;54(3):220-30. 